\title{
Nitrogen-containing secondary organic aerosol formation by acrolein reaction with ammonia/ammonium
}

\author{
Zhijian Li ${ }^{1}$, Sergey A. Nizkorodov ${ }^{2}$, Hong Chen ${ }^{1}$, Xiaohui $\mathrm{Lu}^{1}$, Xin Yang ${ }^{1,3}$, and Jianmin Chen ${ }^{1}$ \\ ${ }^{1}$ Shanghai Key Laboratory of Atmospheric Particle Pollution and Prevention, Department of Environmental \\ Science and Engineering, Fudan University, Shanghai 200433, China \\ ${ }^{2}$ Department of Chemistry, University of California, Irvine, California 92697, USA \\ ${ }^{3}$ Shanghai Institute of Pollution Control and Ecological Security, Shanghai 200092, China
}

Correspondence: Xiaohui Lu (luxiaohui@fudan.edu.cn) and Xin Yang (yangxin@fudan.edu.cn)

Received: 6 September 2018 - Discussion started: 25 September 2018

Revised: 27 December 2018 - Accepted: 18 January 2019 - Published: 1 February 2019

\begin{abstract}
Ammonia-driven carbonyl-to-imine conversion is an important formation pathway to the nitrogen-containing organic compounds (NOCs) in secondary organic aerosols (SOAs). Previous studies have mainly focused on the dicarbonyl compounds as the precursors of light-absorbing NOCs. In this work, we investigated whether acrolein could also act as an NOC precursor. Acrolein is the simplest $\alpha, \beta$ unsaturated mono-carbonyl compound, and it is ubiquitous in the atmosphere. Experiments probing multiphase reactions of acrolein as well as bulk aqueous-phase experiments were carried out to study the reactivity of acrolein towards ammonia and ammonium ions. Molecular characterization of the products based on gas chromatography mass spectrometry, high-resolution mass spectrometry, surface-enhanced Raman spectrometry and ultraviolet/visible spectrophotometry was used to propose possible reaction mechanisms.

We observed 3-methylpyridine (commonly known as 3-picoline) in the gas phase in Tedlar bags filled with gaseous acrolein and ammonia or ammonium aerosols. In the ammonium-containing aqueous phase, oligomeric compounds with formulas $\left(\mathrm{C}_{3} \mathrm{H}_{4} \mathrm{O}\right)_{m}\left(\mathrm{C}_{3} \mathrm{H}_{5} \mathrm{~N}\right)_{n}$ and pyridinium compounds like $\left(\mathrm{C}_{3} \mathrm{H}_{4} \mathrm{O}\right)_{2} \mathrm{C}_{6} \mathrm{H}_{8} \mathrm{~N}^{+}$were observed as the products. The pathway to 3 -methylpyridine was proposed to be the intramolecular carbon-carbon addition of the hemiaminal, which resulted from sequential carbonyl-to-imine conversions of acrolein molecules. The 3-methylpyridine was formed in the aqueous phase, but some of the 3methylpyridine could revolatilize to the gas phase, explaining the observation of gaseous 3-methylpyridine in the bags. The $\left(\mathrm{C}_{3} \mathrm{H}_{4} \mathrm{O}\right)_{2} \mathrm{C}_{6} \mathrm{H}_{8} \mathrm{~N}^{+}$was a carbonyl-to-hemiaminal prod-
\end{abstract}

uct from acrolein dimer and 3-methylpyridine, while the oligomeric products of $\left(\mathrm{C}_{3} \mathrm{H}_{4} \mathrm{O}\right)_{m}\left(\mathrm{C}_{3} \mathrm{H}_{5} \mathrm{~N}\right)_{n}$ were polymers of acroleins and propylene imines formed via carbonylto-imine conversion and condensation reactions. The $\mathrm{pH}$ value effect on the liquid products was also studied in the bulk aqueous-phase experiments. While the oligomeric compounds were forming in both acidic and alkaline conditions, the pyridinium products favored moderately acidic conditions. Both the oligomeric products and the pyridinium salts are light-absorbing materials. This work suggests that acrolein may serve as a precursor of light-absorbing heterocyclic NOCs in SOA. Therefore, secondary reactions of $\alpha, \beta$ unsaturated aldehydes with reduced nitrogen should be taken into account as a source of light-absorbing NOCs in SOA.

\section{Introduction}

Carbonyl compounds are ubiquitous in the gaseous, liquid and particulate phases in the atmosphere (Carlier et al., 1986; Dai et al., 2012; Grosjean, 1982). The high reactivity of carbonyls makes them important intermediates in chemical conversion of volatile organic compounds (VOCs) into secondary organic aerosol (SOA) by multiphase chemical processes. After the uptake to the particulate phase, volatile carbonyls may undergo photooxidation (Renard et al., 2015), aldol condensation (Sareen et al., 2010; Yasmeen et al., 2010), oligomerization (De Haan et al., 2011; Renard et al., 2016; Shen et al., 2016), imine ( $\mathrm{R}=\mathrm{NH}$ compound) or hemiaminal $\left(\mathrm{R}(\mathrm{OH})-\mathrm{NR}_{2}\right.$ compound) formation (Maxut et al., 2015; 
Yu et al., 2011), or Mannich reaction (Nozière and Córdova, 2008; Wang et al., 2010) to form high molecularweight (high-MW) compounds in SOA. For example, compounds that possess two carbonyl groups (dicarbonyls), such as glyoxal and methylglyoxal, are important precursors of aqueous SOA (Galloway et al., 2014; Shapiro et al., 2009; Trainic et al., 2011; Volkamer et al., 2007; Yu et al., 2011; Zhao et al., 2006). A number of laboratory and field studies have highlighted the importance of carbonyl-to-imine reaction for the formation of light-absorbing nitrogen-containing organic compounds (NOCs) from dicarbonyls (De Haan et al., 2011; Hawkins et al., 2018; Lin et al., 2015). Since the two carbonyl groups in dicarbonyls can both undergo the carbonyl-to-imine formation, heterocyclic aromatic NOCs derived from pyrrole, imidazole, pyridine, etc., are formed (Aiona et al., 2017; Bones et al., 2010; Flores et al., 2014; Kampf et al., 2012, 2016; Laskin et al., 2010; O'Brien et al., 2013; Teich et al., 2016; Updyke et al., 2012). The extended conjugation in the resulting NOC compounds leads to the light absorptivity of the SOA particles containing these compounds (Lee et al., 2013).

Mono-carbonyl compounds such as formaldehyde, acetaldehyde, hydroxyacetone and acrolein are important precursors of free radicals, peroxyacetyl nitrates (PANs), ozone and other reactive oxygen species (Mellouki et al., 2015). They can undergo the acid-catalyzed heterogeneous reactions after being taken up into the acidic aerosols (Garland et al., 2006; Jang et al., 2002). Mono-carbonyls can also be converted into light-absorbing SOA compounds via multiphase chemistry. For example, Powelson et al. (2014) investigated the formation of light-absorbing SOA in aqueous reactions of different mono-carbonyl compounds including formaldehyde, acetaldehyde, hydroxyacetone and several dicarbonyl compounds with amines or ammonium salts. Most carbonyl compounds are able to undergo aldol condensation under highly acidic conditions to form oligomers which absorb light in the $300-500 \mathrm{~nm}$ range (Nozière and Esteve, 2007; Van Wyngarden et al., 2015). Previous experiments suggest that the light absorptivity of SOA derived from mono-carbonyl compounds is in general smaller than that from reactions of glyoxal and methylglyoxal. However, mono-carbonyl compounds such as formaldehyde and acetaldehyde were found to increase the production of imidazoles by dicarbonyls (Rodriguez et al., 2017).

The majority of the reactions of carbonyl compounds leading to light-absorbing products involved saturated aldehydes and ketones. Unsaturated mono-carbonyl compounds have received less attention in this regard. Nozière et al. (2006) have investigated the uptake of unsaturated mono-carbonyl compounds such as methyl vinyl ketone and methacrolein onto sulfuric acid solution via aldol condensation. In $\alpha, \beta$ unsaturated mono-carbonyl compounds, such as acrolein, the conjugation of the carbonyl group with the alkene, results in a charge distribution within the molecule that makes both nucleophilic addition and electrophilic addition possible. The reactivity of $\alpha, \beta$-unsaturated mono-carbonyl compounds with amines and ammonia has not been previously explored in an atmospheric chemistry context.

Acrolein is a typical $\alpha, \beta$-unsaturated mono-carbonyl compound with a widespread occurrence in the atmosphere. Acrolein was observed at concentrations comparable to those of acetaldehyde in a coastal region of southern Europe (Cerqueira et al., 2003; Romagnoli et al., 2016). According to ambient measurements by Altemose et al. (2015), the average concentration of acrolein was $2.9 \pm 0.8 \mu \mathrm{g} \mathrm{m}^{-3}$ during the Beijing Olympics. Cahill (2014) found that even the natural background concentration of acrolein in summer in California was higher than $20 \mathrm{ng} \mathrm{m}^{-3}$. Acrolein arises from vehicular emissions (Grosjean et al., 2001), wood combustion (Lipari et al., 1984), cooking oil heating (Umano and Shibamoto, 1987), smoking (Feng et al., 2006) and other sources (Ho and Yu, 2002; Reda et al., 2015; Seaman et al., 2007). It is also one of the products of atmospheric photooxidation of other VOCs such as 1,3-butadiene (Baker et al., 2005; Liu et al., 1999; Tuazon et al., 1999). The atmospheric lifetime of acrolein is $>6$ days for photolysis and a few hours for $\mathrm{OH}$ radical reaction (Magneron et al., 2002). The $\mathrm{OH}$-initiated oxidation of acrolein in the presence of $\mathrm{NO}_{x}$ leads to the formation of PAN-type species (Magneron et al., 2002; Orlando and Tyndall, 2002). The reactive uptake of acrolein on aerosols containing ammonium sulfate, if effective, could potentially act as an alternative sink for acrolein as well as a source of particulate organic compounds, including NOCs.

The goal of this work is to improve our understanding of SOA formation from $\alpha, \beta$-unsaturated carbonyls. We are reporting results of experiments on the reactive uptake of acrolein by aqueous aerosols as well as bulk solutions containing ammonium sulfate, the most abundant inorganic salt in the atmosphere. Possible mechanisms of chemical reactions of acrolein with ammonia or ammonium are proposed based on the molecular characterization of the reaction products using mass spectrometry. The results suggest that acrolein + ammonia/ammonium reactions may lead to lowvolatility NOCs in SOA.

\section{Experiments}

\subsection{Tedlar bag experiments}

Tedlar bag experiments were carried out to study the reaction of acrolein with ammonia/ammonium. Four inflatable Tedlar bags with maximum volumes of $100 \mathrm{~L}$ were prepared. One was labeled acrolein-ammonia bag, two were labeled acrolein-ammonium bags, and one was used for control experiments. We prepared a $0.15 \mathrm{M}$ acrolein solution in water, a $2.2 \mathrm{M}$ ammonium hydroxide solution, and $1 \mathrm{M}\left(\mathrm{NH}_{4}\right)_{2} \mathrm{SO}_{4}$ and $2 \mathrm{M} \mathrm{NH}_{4} \mathrm{Cl}$ aqueous solutions in advance. We referred to the added nitrogen in this work as "total ammonia" (includ- 
ing both the ammonia $\mathrm{NH}_{3}$ and ammonium ions $\mathrm{NH}_{4}^{+}$). By evaporating $2 \mathrm{~mL}$ of the acrolein solution and $400 \mu \mathrm{L}$ of the ammonium hydroxide solution in the water bath at $40^{\circ} \mathrm{C}$, nearly $5 \mathrm{mmol}$ total ammonia and $0.3 \mathrm{mmol}$ acrolein were introduced into the acrolein-ammonia bag. For the acroleinammonium bags, $2 \mathrm{~mL}$ of the acrolein solution was evaporated into each bag as well. However, particles containing ammonium ions were added to the acrolein-ammonium bag instead of gaseous ammonia. These particles were generated by aerosolizing about $2 \mathrm{~mL}$ of $1 \mathrm{M}\left(\mathrm{NH}_{4}\right)_{2} \mathrm{SO}_{4}$ or $2 \mathrm{M} \mathrm{NH}_{4} \mathrm{Cl}$ aqueous solutions (about $4 \mathrm{mmol}$ total ammonia) in a TSI atomizer (Model 9302). The size of the generated aerosols peaked around $800 \mathrm{~nm}$, as shown in Fig. S1 in the Supplement. The size distribution was measured by a TSI aerodynamic particle sizer spectrometer (Model 3321). Dry $\mathrm{N}_{2}$ from the gas cylinders was used for filling the bags to their maximum volume of $100 \mathrm{~L}$. The relative humidity $(\mathrm{RH})$ in the bags was measured as $90 \%-100 \%$. The bags were stored under dark conditions at room temperature for $2 \mathrm{~h}$ prior to analysis.

The $4 \mathrm{~mL}$ of water evaporated/aerosolized in the $100 \mathrm{~L} \mathrm{bag}$ volume in acrolein-ammonium experiments provided more than enough water to maintain saturated conditions with respect to water vapor and to sustain a liquid film on the bag walls. The aerosolized $\left(\mathrm{NH}_{4}\right)_{2} \mathrm{SO}_{4}$ or $\mathrm{NH}_{4} \mathrm{Cl}$ particles can be expected to deposit on the bag walls, at least partially, after some time. Because the RH was higher than the deliquescence points $(80 \%)$ of the salts (Takahama et al., 2007), the wall coating likely existed as an aqueous film containing dissolved ammonium ions on the inner surface of the bag. Therefore, the gas-phase constituents and the constituents of the aqueous film were both collected for analysis. The RH in the acrolein-ammonia experiments was also high, around $90 \%$, because $\sim 2 \mathrm{~g} \mathrm{H}_{2} \mathrm{O}$ vapor was also added to the bag when evaporating $2 \mathrm{~mL}$ of the acrolein solution and $400 \mu \mathrm{L}$ of the ammonium hydroxide solution. Because of the high RH, the acrolein and ammonia in the acrolein-ammonia bag could partition into both the gas phase and the liquid film on the bag wall. (The Henry's constants for acrolein and for ammonia are $\sim 8$ and $\sim 60 \mathrm{~mol} \mathrm{~L}^{-1} \mathrm{~atm}^{-1}$, respectively.). Therefore, the wall residues were analyzed in these experiments as well.

The gas-phase constituents in the bags were analyzed by gas chromatography mass spectrometry (GC-MS; Thermo Focus DSQ). A solid-phase micro-extraction (SPME) fiber (50/30 $\mu \mathrm{m}$ DVB/CAR/PDMS $2 \mathrm{~cm}$, Supelco) was inserted directly into the bag for $15 \mathrm{~min}$ after the bag was stored for $2 \mathrm{~h}$. The SPME-collected constituents were desorbed at $250^{\circ} \mathrm{C}$ for $2 \mathrm{~min}$ and measured by GC-MS. The temperature program used for GC-MS analysis was as follows: $60^{\circ} \mathrm{C}$ for $3 \mathrm{~min}$, followed by a linear ramp to $300^{\circ} \mathrm{C}$ at $30^{\circ} \mathrm{C} \mathrm{min}^{-1}$, followed by $2 \mathrm{~min}$ at $300^{\circ} \mathrm{C}$. Helium $(99.999 \%$ ) was the carrier gas maintained at a flow rate of $1 \mathrm{~mL} \mathrm{~min}^{-1}$. A splitless mode was used. The electron impact energy was $70 \mathrm{eV}$ and the mass-to-charge range was $m / z 41-400$ in the full- scan acquisition mode. Compounds were identified using the NIST Mass Spectral Library (National Institute of Standards and Technology, Washington, DC, USA). The basic properties of chemicals such as the Henry's constant of acrolein and 3-methylpyridine and their typical ultraviolet-visible (UVvis) spectra were obtained from NIST Chemistry WebBook, Standard Reference Database Number 69.

The constituents in the aqueous film on the bag walls were analyzed by an electrospray ionization high-resolution mass spectrometer (ESI HRMS, Agilent 6540, with mass resolving power of 40000 ). The residue remaining on the bag walls was rinsed by $1 \mathrm{~mL}$ acetonitrile/water $(1 / 1, v / v)$ and then rapidly detected by direct infusion ESI HRMS in the positive mode. The parameters used for the mass spectrometer were the following: spray voltage $3000 \mathrm{~V}$; sweep gas flow rate 0 respective arbitrary units (AU); sheath gas flow rate $10 \mathrm{AU}$; aux gas flow rate $5 \mathrm{AU}$; ion transfer tube temperature $350^{\circ} \mathrm{C}$; vaporizer temperature $300^{\circ} \mathrm{C}$; scan range $\mathrm{m} / \mathrm{z} 50$ 500; maximum injection time $100 \mathrm{~ms}$; automated gain control (AGC) target 250000 ; S-lens radio frequency (RF) level $60 \%$. The major ion peaks were assigned as protonated formulas $\mathrm{C}_{c} \mathrm{H}_{h+1} \mathrm{O}_{o} \mathrm{~N}_{n}^{+}(c \geq 5, h \geq 5,0 \leq o \leq 10,0 \leq n \leq 10)$ using the Agilent MassHunter Qualitative Analysis B.07.00. The mass accuracy limit was set to $\pm 3 \mathrm{ppm}$, and the ratio of the double-bond equivalent (DBE) value to the number of carbon atoms (C number) was constrained to be less than 0.7. Since most compounds were detected as protonated ions, $\mathrm{C}_{c} \mathrm{H}_{h+1} \mathrm{O}_{o} \mathrm{~N}_{n}^{+}$, the DBE value of the neutral compound $\mathrm{C}_{c} \mathrm{H}_{h} \mathrm{O}_{o} \mathrm{~N}_{n}$ was calculated as $c+1-(h-n) / 2$.

\subsection{Bulk aqueous-phase experiments}

Bulk aqueous-phase experiments were carried out to study the reaction of acrolein with ammonium ion in solution. Solutions containing $1 \mathrm{M}$ of ammonium ion with different $\mathrm{pH}$ values were prepared by mixing different volumes of ammonium hydroxide and hydrochloric acid. A volume of $25 \mu \mathrm{L}$ of acrolein was then mixed into the $5 \mathrm{~mL}$ of the solution to achieve an initial acrolein concentration of $75 \mathrm{mM}$. All solution mixtures were kept in capped glass bottles in the dark at room temperature for $2 \mathrm{~h}$. For UV-vis measurements, the reaction time was set to $30 \mathrm{~min}, 1 \mathrm{~h}, 2 \mathrm{~h}$ and $4 \mathrm{~h}$.

Since the amount of sample was much larger than in the Tedlar bag experiments, several additional types of analysis including ultrahigh-performance liquid chromatography (UPLC) coupled with ESI HRMS, surface-enhanced Raman spectrometry (SERS) and conventional UV-vis spectrophotometry could be applied to the constituents of the bulk sample at the end of reaction. The solutions after reaction were diluted by a factor of 20 with deionized water. The constituents were separated by a UPLC column (Agilent ZORBAX SB-C18 HD, $50 \times 2.1 \mathrm{~mm}$ ) and detected by ESI HRMS (Agilent 6540). The eluent composition was $(A)$ Milli-Q grade water and $(B)$ acetonitrile at a flow rate of $0.6 \mathrm{~mL} \mathrm{~min}^{-1}$. The mobile-phase gradient was initially $95: 5$ 
$(v / v, A / B)$, increased to $100 \% B$ in $15 \mathrm{~min}$ and returned to $95: 5(v / v, A / B)$ in $1 \mathrm{~min}$ and then was kept there for $4 \mathrm{~min}$ to re-equilibrate the column. We also carried out the formula assignment for the MS-measured reactants and products. For SERS analysis, $500 \mu \mathrm{L}$ of the solution was mixed with a certain concentration of gold nanoparticles, and $100 \mu \mathrm{L}$ of the mixture was then dropped on the silicon wafer and dried in air for measurement by a LabRam-1B Raman spectrometer. Absorption spectra of the bulk samples were measured by a conventional UV-vis spectrophotometer (U-3000, Hitachi). The scan range of the spectrometer was set to $190-700 \mathrm{~nm}$, a quartz cuvette with an optical path length of $1 \mathrm{~cm}$ was used, and deionized water was used as the reference solution.

\section{Results and discussion}

\subsection{Analysis of gaseous components in the acrolein-ammonia and acrolein-ammonium bags}

Figure 1 shows GC traces for the gas-phase compounds in the acrolein-ammonia bag, in the acrolein-ammonium bag and in the control experiment (in which only acrolein was introduced into the bag). For the control experiment, two species were separated at the retention times 1.59 and $4.27 \mathrm{~min}$. With help of the NIST library, the 1.59 min peak was identified as acrolein, and the 4.27 min peak as pyran aldehyde. Pyran aldehyde is a known acrolein dimer generated via DielsAlder reaction (Reaction R1 in Fig. 2). The dimer is commonly found in acrolein-containing solutions, and it is easier to quantify than acrolein (for example, it was used as the marker for the detection of acrolein in wine) (Bauer et al., 2010, 2012). In the control experiment, acrolein existed in the bag for $2 \mathrm{~h}$. The Diels-Alder reaction likely occurred on the wetted surface of the bag or in the solution before injection into the bag, and the dimer evaporated back into the gas phase (although we cannot rule out gas-phase reaction).

The chromatogram of the gaseous components in the acrolein-ammonia bag was different from that of the control experiment. Pyran aldehyde was still observed but as an inconspicuous peak, as shown in Fig. 1b. Two strong chromatographic peaks occurred at retention times of 1.60 and $4.18 \mathrm{~min}$. The former corresponds to acrolein while the latter could be identified as 3-methylpyridine, also known as 3-picoline. As a confirmation, the 3-methylpyridine standard was detected by the same GC-MS instrument at the same retention time, shown in Fig. 1c. 3-Methylpyridine was also observed in Fig. 1d as one of the gaseous components in the acrolein-ammonium bag but with a smaller abundance than that in the acrolein-ammonia bag.

In the organic chemistry studies, it is known that pyridine and its derivatives can be synthesized from $\alpha, \beta$-unsaturated aldehydes or ketones with ammonia through multistep chemistry, usually including imine formation, aldol condensation and Michael reaction (Brody and Ruby, 1960; Stitz, 1942;
Tschitschibabin, 1924; Tschitschibabin and Oparina, 1927; Zhang et al., 2014, 2016). However, all these reported syntheses in either gas phase or liquid phase required elevated temperatures and/or the presence of an acidic solid-state catalyst. The formation of 3-methylpyridine from acrolein under room temperature conditions and without a catalyst has not been reported before. Kampf et al. (2016) have reported the formation of methylpyridine as an organic aerosol compound from glutaraldehyde (a 1,5-dicarbonyl compound) undergoing sequential carbonyl-to-imine reactions, similar to the Paal-Knorr pyrrole formation from 1,4-dicarbonyls. However, this mechanism would not work for acrolein, which is a mono-carbonyl with only three carbon atoms. Dihydropyridine compounds were also found in the mixture of acetaldehyde, acetylacetone and ammonia sulfate by Kampf et al. (2016). Both carbonyl-to-imine conversion and the condensation of acetaldehyde and acetylacetone derivatives contributed to the dihydropyridine formation.

The 3-methylpyridine formation in our work could also be a combined result of condensation and imine formation. We propose the pathway for the 3-methylpyridine formation in Reaction (R2) in Fig. 2. An acrolein molecule is converted into propylene imine by carbonyl-to-imine conversion and then undergoes the carbonyl-to-imine conversion again with another acrolein molecule to form a hemiaminal. The $\beta$-carbon in one alkenyl group has a lower electronegativity than the $\alpha$-carbon in the other alkenyl group, leading to the intramolecular addition reaction between them. Thus, a methylpyridine is generated after the addition reaction and the subsequent dehydration. This proposed pathway leads to the formation of 3-methylpyridine, which is identified as the main product in our experiments, rather than its isomeric 2- or 4-methylpyridine. Moreover, the pathway is similar to the mechanism Stitz (1942) proposed for the synthesis of 3methylpyridine in the gas phase, but Stitz's work involved the temperature higher than $110^{\circ} \mathrm{C}$ and the catalyst. Our observation of similar reaction products under ambient temperature conditions suggests that conversion of acrolein into NOCs may slowly take pace without a catalyst under atmospherically relevant conditions.

The design of the experiments makes it challenging to determine whether the proposed reaction is occurring in the gas phase or in the liquid phase. The gaseous 3-methylpyridine was detected in both the acrolein-ammonium bag and the acrolein-ammonia bag. In both types of experiments, ammonia was present in the gas phase and ammonium ions were present in the liquid film on the bag walls. An important clue is that, in addition to the observed gaseous 3-methylpyridine, the pyridinium products were observed in the liquid film on the wall of the acrolein-ammonium bag (see Sect. 3.2). Hence, we propose that Reaction (R2) occurred in the liquid phase in our experiments (although we cannot rule out a gas-phase reaction.) The gaseous 3-methylpyridine results from the liquid-to-gas partitioning equilibrium promoted by 


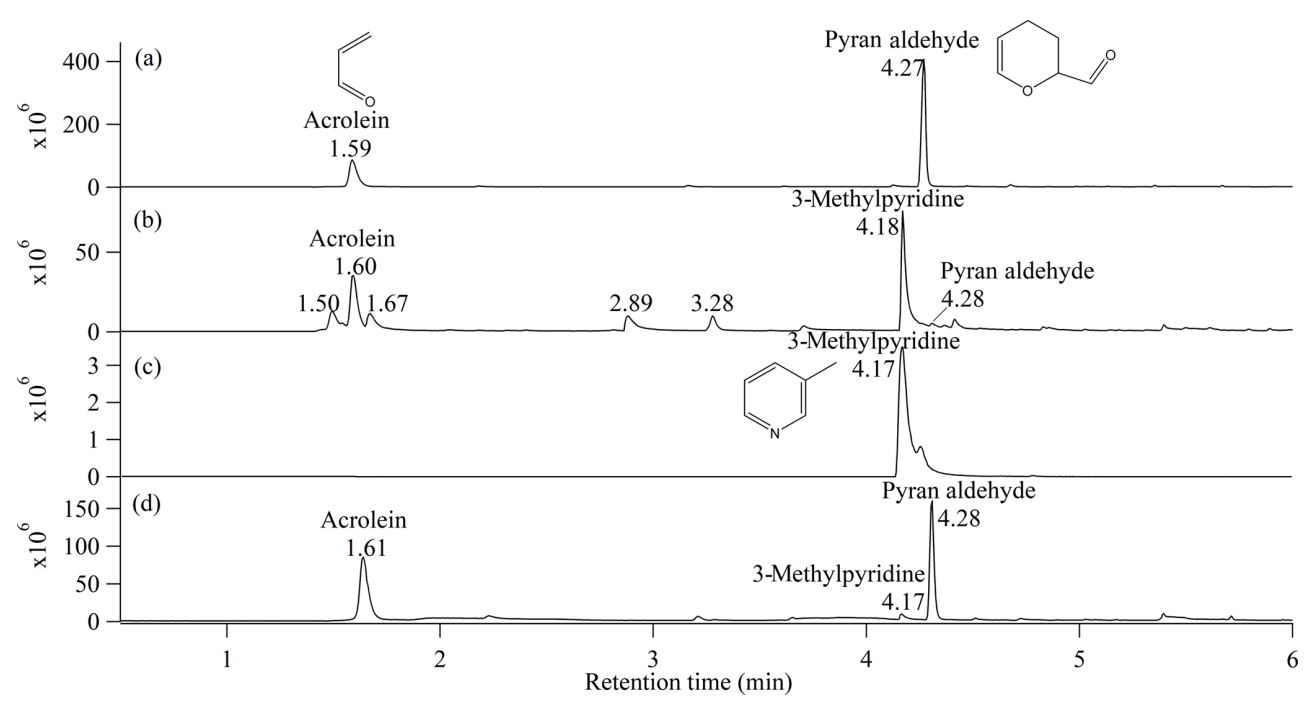

Figure 1. GC traces for: (a) the gaseous components in the control experiment with acrolein only; (b) the gaseous components in the acroleinammonia bag; (c) standard 3-methylpyridine; (d) the gaseous components in the acrolein-ammonium bag using $\left(\mathrm{NH}_{4}\right)_{2} \mathrm{SO}_{4}$. The retention times and important compounds identified by NIST library are labeled. The GC-MS results for the acrolein-ammonium experiment using $\mathrm{NH}_{4} \mathrm{Cl}$ produced results that were very similar to (d), so they are not included here. The corresponding MS patterns for the main peaks are shown in Fig. S2.

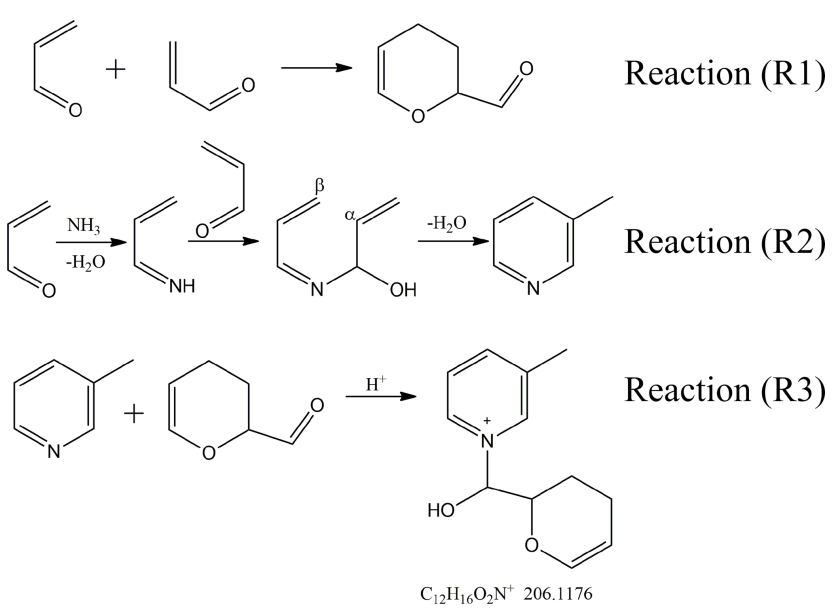

Figure 2. Proposed reactions of acrolein with ammonia or ammonium ion that explain the products observed in this work.

the limited solubility of 3-methylpyridine (its Henry's constant is $\sim 54 \mathrm{~mol} \mathrm{~L}^{-1} \mathrm{~atm}^{-1}$ ).

In addition to peaks for the reactant of acrolein and product of 3-methylpyridine, four smaller peaks were observed at 1.50, 1.67, 2.89 and 3.28 min in Fig. 1b. The MS pattern for the peak at $1.67 \mathrm{~min}$ failed to match any known chemical, but the remaining three were identified as acetaldehyde, pyridine and allyl acrylate, respectively. Some acrolein likely underwent the aqueous-phase decomposition back to acetaldehyde and formaldehyde in the prepared solution or in the aqueous film on the bag wall, leading to the detection of acetaldehyde after liquid-to-gas phase partitioning. The allyl acrylate as a by-product could be attributed to the acrolein condensation, though the reported allyl acrylate formation by acrolein requires a catalyst (Youngman and Rust, 1961). The observed pyridine would require methylpyridine demethylation, but how the demethylation happened is not clear.

\subsection{Analysis of condensed-phase products of acrolein reaction with ammonium in the liquid film}

Considering that the high humidity in the bag produced a liquid film on the bag wall, we examined the composition in the liquid film to study the condensed-phase products. The direct infusion ESI HRMS results for the bag-wall residue samples and for a standard acrolein solution are displayed in Fig. 3 . For acrolein itself, the spectra were dominated only by the strong signal at $m / z, 113.0597$, corresponding to $\left[\mathrm{C}_{6} \mathrm{H}_{9} \mathrm{O}_{2}\right]^{+}$ by the formula assignment. As pyran aldehyde $\mathrm{C}_{6} \mathrm{H}_{8} \mathrm{O}_{2}$ is a known dimer of acrolein and is also observed in the gaseous sample by GC-MS, the $\left[\mathrm{C}_{6} \mathrm{H}_{9} \mathrm{O}_{2}\right]^{+}$is assigned protonated pyran aldehyde.

The bag-wall residue samples had more peaks in their mass spectra, extending all the way to $m / z$ 500. We carried out the formula assignment for the top 30 peaks for each mass spectrum. The assignments are listed in Table S1 and shown in Fig. 4 by plotting the DBE value versus $C$ number in the assigned formulae of unionized species (the $\mathrm{H}^{+}$or $\mathrm{NH}_{4}^{+}$were removed from the ion formula). The orderly distribution of the observed $\mathrm{C}$ numbers in multiples of three in Fig. 4 implies oligomerization of $\mathrm{C}_{3}$ compounds. The formula of acrolein is $\mathrm{C}_{3} \mathrm{H}_{4} \mathrm{O}$, and propylene imine (the unstable intermediate product of reaction between acrolein 


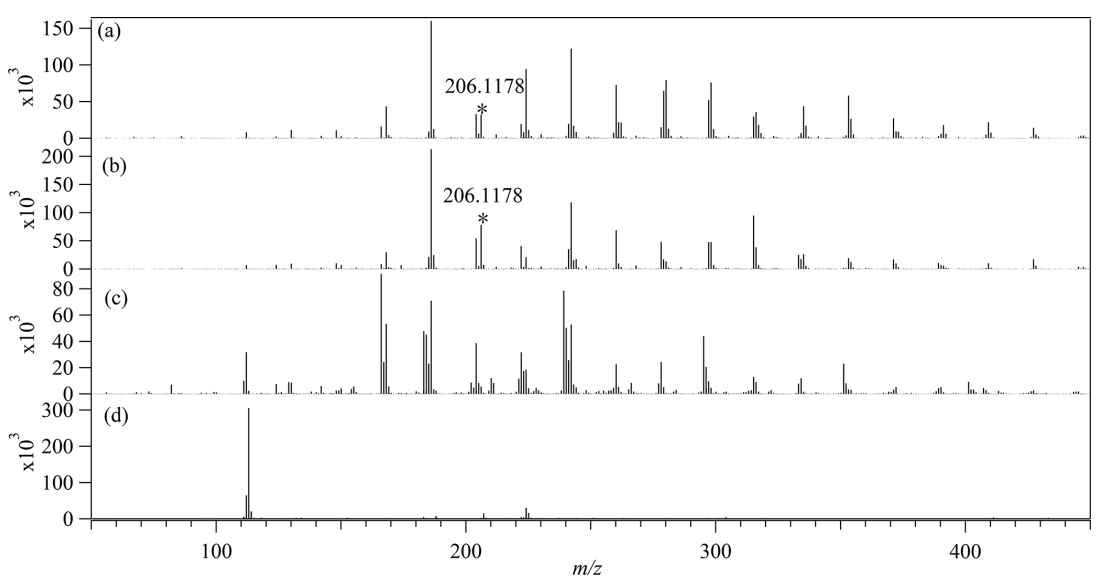

Figure 3. The direct-infusion ESI high-resolution mass spectra for the bag-wall residue samples in (a) the acrolein-ammonium $\mathrm{NH}_{4} \mathrm{Cl}$ bag, (b) the acrolein-ammonium $\left(\mathrm{NH}_{4}\right)_{2} \mathrm{SO}_{4}$ bag and (c) the acrolein-ammonia bag. (d) The mass spectrum for the acrolein standard. The peaks at $m / z 206.1178$ assigned to the pyridinium compounds $\left(\mathrm{C}_{3} \mathrm{H}_{4} \mathrm{O}\right)_{2} \mathrm{C}_{6} \mathrm{H}_{8} \mathrm{~N}^{+}$are labeled with asterisks.

and ammonia) has a formula $\mathrm{C}_{3} \mathrm{H}_{5} \mathrm{~N}$. The compounds in the residue samples appeared to represent the oligomerization products between several acrolein and propylene imine molecules, though the reaction pathway to the oligomers was unclear. It is easy to show that simple addition oligomers with formulas $\left(\mathrm{C}_{3} \mathrm{H}_{4} \mathrm{O}\right)_{m}\left(\mathrm{C}_{3} \mathrm{H}_{5} \mathrm{~N}\right)_{n}$ have a DBE of $m+n+1=$ $(1 / 3) \times C$ number +1 . Because the addition oligomers could be additionally hydrated or ammoniated, the observed DBE can be below the $(1 / 3) \times \mathrm{C}$ number +1 prediction. As shown in Fig. 4, the majority of the assigned compounds were located in the region of " $\mathrm{DBE} \leq 1 / 3 \mathrm{C}$ number +1 ", suggesting that the $\left(\mathrm{C}_{3} \mathrm{H}_{4} \mathrm{O}\right)_{m}\left(\mathrm{C}_{3} \mathrm{H}_{5} \mathrm{~N}\right)_{n}$ oligomers are the main products of liquid-phase reaction between acrolein and ammonium. The ions detected in the bag-wall residues in the acrolein-ammonia bag differed from those ions detected in the acrolein-ammonium bag (Fig. 4). The bag-wall sample in the acrolein-ammonia bag contained the oligomers with lower molecular weight and comparatively more $\mathrm{N}$ atoms. This is consistent with ammonia (as opposed to ammonium) driving the oligomerization chemistry.

As we discussed in the previous section, gaseous 3methylpyridine observed by GC-MS comes from the phase partitioning of the 3-methylpyridine formed in the liquid phase. Therefore, 3-methylpyridine and related compounds derived from it ought to be present in the bag-wall samples. The higher DBE values resulting from the pyridine ring in these compounds make it possible to distinguish them from the $\left(\mathrm{C}_{3} \mathrm{H}_{4} \mathrm{O}\right)_{m}\left(\mathrm{C}_{3} \mathrm{H}_{5} \mathrm{~N}\right)_{n}$ oligomers of acrolein and propylene imine molecules. In Fig. 4, the bag-wall residue sample in the acrolein-ammonium bags contained some organics located above the "DBE $=1 / 3 \mathrm{C}$ number +1 " line, indicating the presence of these heterocyclic compounds. The ion at $m / z 206.1178$ has the highest MS abundance among these high-DBE ions, and it corresponds to $\left[\mathrm{C}_{12} \mathrm{H}_{16} \mathrm{ON}_{2}\right]^{+}$ by the formula assignment. Its formula can be also pre- sented as $\left(\mathrm{C}_{3} \mathrm{H}_{4} \mathrm{O}\right)_{2} \mathrm{C}_{6} \mathrm{H}_{8} \mathrm{~N}^{+}$to emphasize that it is related to methylpyridine $\left(\mathrm{C}_{6} \mathrm{H}_{7} \mathrm{~N}\right)$. We propose the following pathway to $\left(\mathrm{C}_{3} \mathrm{H}_{4} \mathrm{O}\right)_{2} \mathrm{C}_{6} \mathrm{H}_{8} \mathrm{~N}^{+}$: Reaction (R2) in Fig. 2 leads to the formation of 3-methylpyridine, and then the lone pair on the pyridine nitrogen can attack the electrophilic site in the carbonyl of the acrolein dimer to change the carbonyl to hemiaminal and form pyridinium compounds $\left(\mathrm{C}_{3} \mathrm{H}_{4} \mathrm{O}\right)_{2} \mathrm{C}_{6} \mathrm{H}_{8} \mathrm{~N}^{+}$ (Reaction R3 in Fig. 2).

The $\left(\mathrm{C}_{3} \mathrm{H}_{4} \mathrm{O}\right)_{2} \mathrm{C}_{6} \mathrm{H}_{8} \mathrm{~N}^{+}$observed in the bag-wall residue sample in the acrolein-ammonium bag demonstrated the formation of pyridine ring compounds in the liquid phase via the proposed Reactions (R2) and (R3). However, we did not observe any heterocyclic compounds with DBE larger than " $1 / 3 \times \mathrm{C}$ number +1 " for the bag-wall residue sample in the acrolein-ammonia bag. In addition to the possible detection limits, $\mathrm{pH}$ effect is the main cause, and it will be discussed in the following section.

\section{3 $\mathrm{pH}$ dependence of the formation of liquid products by acrolein reaction with ammonium}

As the previous two sections demonstrated, polymers $\left(\mathrm{C}_{3} \mathrm{H}_{4} \mathrm{O}\right)_{m}\left(\mathrm{C}_{3} \mathrm{H}_{5} \mathrm{~N}\right)_{n}$ and pyridinium compounds were formed in the ammonium-containing liquid film, and the semi-volatile 3-methylpyridine could partition back to the gas phase. However, in the acrolein-ammonia bag, where the liquid film on the bag wall also contained ammonium ions, no pyridinium compounds were observed in the bag-wall residue sample. The difference in the aqueous film $\mathrm{pH}$ values is the possible cause. The formation of imidazole chromophores and other light-absorbing NOCs in reactions involving ammonia has been demonstrated to be $\mathrm{pH}$-dependent by several reports (Kampf et al., 2012; Phillips et al., 2017; Yu et al., 2011). In the Tedlar bag experiments, the liquid film on the acrolein-ammonia bag wall was alkaline. As the pKa of 3-methylpyridinium is 5.68 (at $20^{\circ} \mathrm{C}$ ), under alka- 


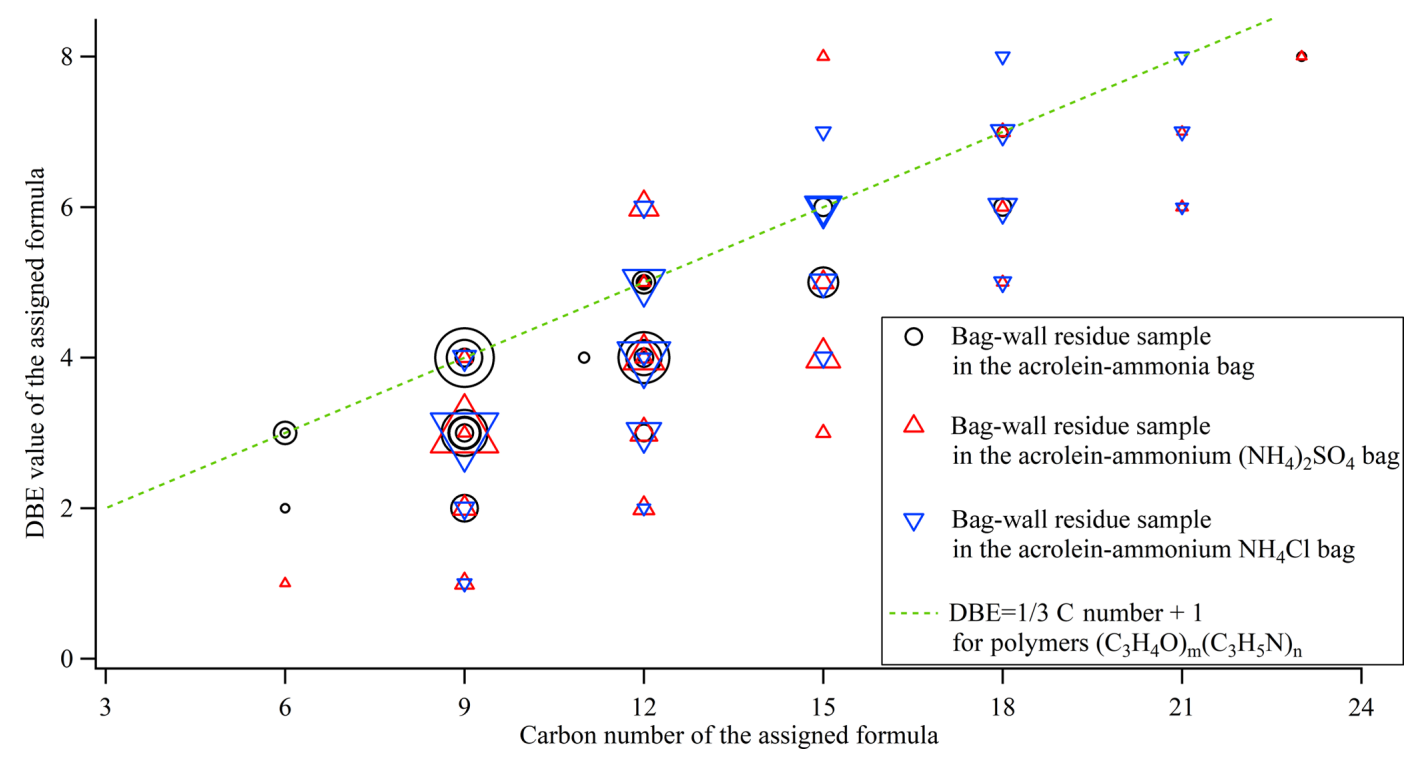

Figure 4. The DBE values versus the carbon number of the assigned formulae for the top 30 peaks in each mass spectrum in Fig. 3. The marker size is proportional to the HRMS peak abundance.

line conditions, the products of Reaction (R2) in the liquid film predominantly exist as the neutral molecules of 3methylpyridine rather than 3-methylpyridinium cations and more easily volatilize to the gas phase. This explains the observation of large levels of 3-methylpyridine by GC-MS but no 3-methylpyridinium cations detectable by ESI HRMS for the acrolein-ammonia bag. In order to more thoroughly investigate the role of the solution $\mathrm{pH}$ in the reaction of acrolein with ammonium, we carried out bulk aqueous experiments at different $\mathrm{pH}$ values.

The UPLC traces for the products observed in bulk aqueous experiments with various $\mathrm{pH}$ values are illustrated in Fig. 5. The chromatograms are quite different for the highly acidic ( $\mathrm{pH}$ of 2-4), moderately acidic and neutral ( $\mathrm{pH}$ of 57 ), and alkaline ( $\mathrm{pH}$ of 8-12) conditions, confirming that the reaction mechanisms are $\mathrm{pH}$-dependent.

At a pH of 10 or 12, the most abundant eluate was detected at the retention time around $1.2 \mathrm{~min}$. The mass spectra at this elution time, shown in Fig. S3, demonstrated that they were trimers of propylene imines. The eluate around $4.8 \mathrm{~min} \mathrm{had}$ the second-strongest ion signal (which was also the strongest peak at $\mathrm{pH}$ of 8), and other small peaks were also observed around $0.6,2.3$ and $3.4 \mathrm{~min}$. Their mass spectra were dominated by the protonated ions and ammonium adduct ions of $\left(\mathrm{C}_{3} \mathrm{H}_{4} \mathrm{O}\right)\left(\mathrm{C}_{3} \mathrm{H}_{5} \mathrm{~N}\right)_{3}$ and $\left(\mathrm{C}_{3} \mathrm{H}_{4} \mathrm{O}\right)_{2}\left(\mathrm{C}_{3} \mathrm{H}_{5} \mathrm{~N}\right)_{3}$. Based on these observations, we can conclude that oligomers of propylene imine and acrolein molecules are the major products formed from acrolein with ammonia under alkaline conditions. At $\mathrm{pH}=8$, though still alkaline, the eluate with the strongest signal intensity was $\left(\mathrm{C}_{3} \mathrm{H}_{4} \mathrm{O}\right)_{2}\left(\mathrm{C}_{3} \mathrm{H}_{5} \mathrm{~N}\right)_{3}$ at retention time around $4.8 \mathrm{~min}$. Trimers of propylene imines were still de- tected but were eluted a little earlier than those in the $\mathrm{pH}=10$ sample.

When the $\mathrm{pH}$ decreased to $5-7$, the chromatographic traces changed drastically. The pyridinium compound $\left(\mathrm{C}_{3} \mathrm{H}_{4} \mathrm{O}\right)_{2} \mathrm{C}_{6} \mathrm{H}_{8} \mathrm{~N}^{+}$became the most abundant eluate, as shown in Fig. 6. The $\left(\mathrm{C}_{3} \mathrm{H}_{4} \mathrm{O}\right)_{2} \mathrm{C}_{6} \mathrm{H}_{8} \mathrm{~N}^{+}$ion was eluted at $0.8 \mathrm{~min}$ in its extracted ion chromatogram, but the totalions chromatogram showed as a bimodal peak (at 0.7 and $1.0 \mathrm{~min}$ ), suggesting that a mixture of other oligomers coeluted at the same time. The $0.7 \mathrm{~min}$ peak had a mixture of $\left(\mathrm{C}_{3} \mathrm{H}_{4} \mathrm{O}\right)_{2} \mathrm{C}_{6} \mathrm{H}_{8} \mathrm{~N}^{+}$and trimers of propylene imines, and the $1.0 \mathrm{~min}$ peak had two pyridinium compounds $\left(\mathrm{C}_{3} \mathrm{H}_{4} \mathrm{O}\right)_{2} \mathrm{C}_{6} \mathrm{H}_{8} \mathrm{~N}^{+}$and $\left(\mathrm{C}_{9} \mathrm{H}_{10} \mathrm{O}_{2}\right) \mathrm{C}_{6} \mathrm{H}_{8} \mathrm{~N}^{+}$as well as other oligomers. The $\left(\mathrm{C}_{9} \mathrm{H}_{10} \mathrm{O}_{2}\right) \mathrm{C}_{6} \mathrm{H}_{8} \mathrm{~N}^{+}$here could be the dehydrated form of $\left(\mathrm{C}_{3} \mathrm{H}_{4} \mathrm{O}\right)_{3} \mathrm{C}_{6} \mathrm{H}_{8} \mathrm{~N}^{+}$. In addition, polymers $\left(\mathrm{C}_{3} \mathrm{H}_{4} \mathrm{O}\right)_{m}\left(\mathrm{C}_{3} \mathrm{H}_{5} \mathrm{~N}\right)_{n}$ were still detected as the peak at $4.8 \mathrm{~min}$. Hence, neutral or mildly acidic conditions improve the yield of pyridinium compounds in the liquid phase.

For the $\left(\mathrm{NH}_{4}\right)_{2} \mathrm{SO}_{4}$ or $\mathrm{NH}_{4} \mathrm{Cl}$ solutions aerosolized into the Tedlar bag, the film pH should be 4.6-6 at $\mathrm{RH}=90 \%$ $100 \%$ according to the E-AIM model (http://www.aim.env. uea.ac.uk/aim/aim.php, last access: 30 January 2019). Therefore, we compared the MS results for the bag-wall residue sample and for the bulk aqueous reactions at $\mathrm{pH}=6$ and 5 . Most of the peaks for the bag-wall residue sample were similar to the one in the bulk solution, except for the strongest ion $\left[\left(\mathrm{C}_{3} \mathrm{H}_{4} \mathrm{O}\right)_{3}+\mathrm{NH}_{4}\right]^{+}$at $m / z \quad 186.1125$. The acrolein trimers detected in the bag-wall residue were not detected in the bulk solution. This difference could be due to the more complete reaction in the bulk experiments. Since the bulk solution was sealed in a bottle with a relatively small headspace to undergo the aqueous-phase reactions, the volatile or semi- 


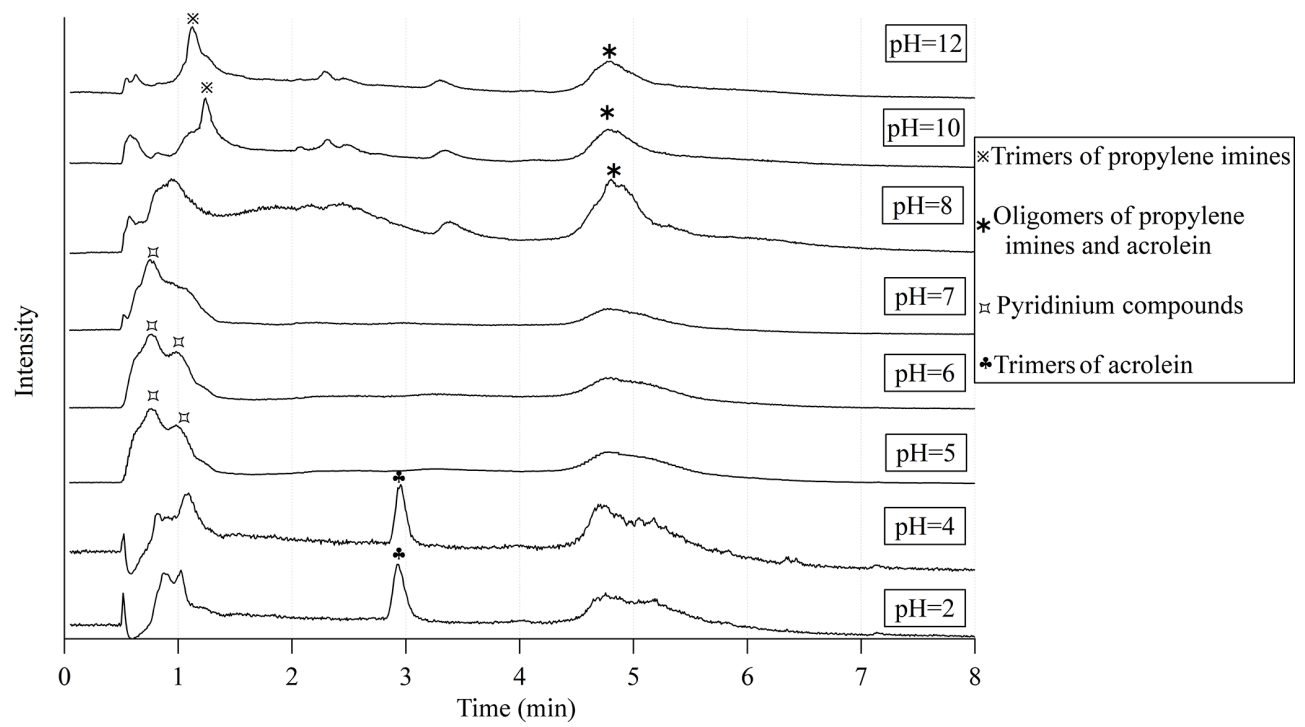

Figure 5. The total ion chromatographic traces of UPLC for samples in bulk solutions with different $\mathrm{pH}$ values. The main peaks are labeled with their corresponding species. The detailed mass spectra for these peaks are shown in Figs. 6, S3 and S4.

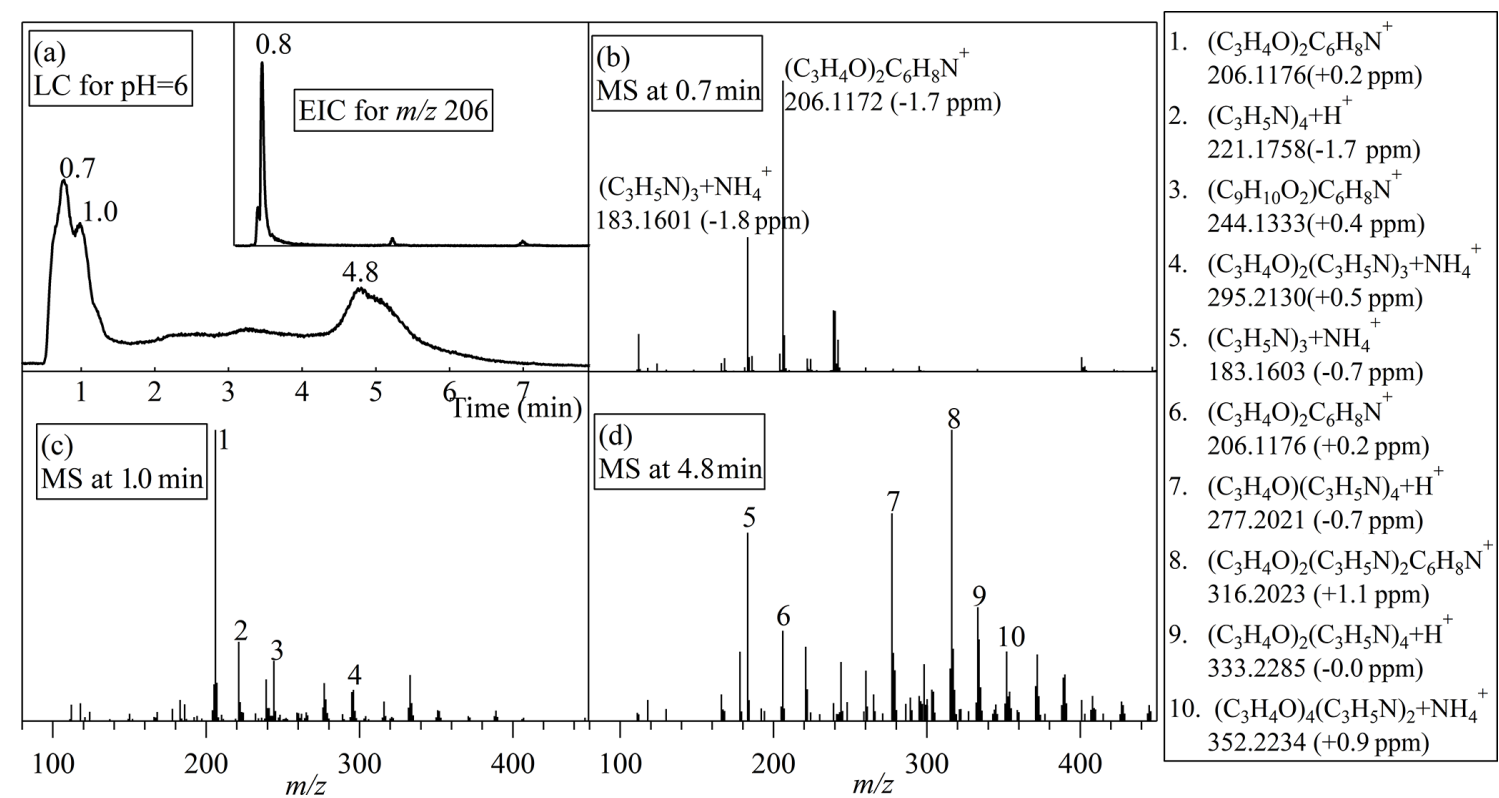

Figure 6. The UPLC HRMS results for the acrolein reaction with ammonium in the mildly acidic bulk solution. (a) A liquid chromatographic (LC) trace for a bulk solution sample with $\mathrm{pH}=6$. The insert is the extracted ion chromatogram (EIC) for $m / z$ 206. (b-d) The mass spectra for the peaks around 0.7, 1.2 and $4.8 \mathrm{~min}$. The $\mathrm{m} / \mathrm{z}$ values and the corresponding assigned formulae for the main ions are marked. The figures in the parentheses are the fractional deviations between the detected and theoretical $\mathrm{m} / \mathrm{z}$ of the assigned ionic formulas.

volatile products or intermediate products could not evaporate into the gas phase as sufficiently as they could in the Tedlar bag experiments. This enhanced the contribution of volatile and semi-volatile compounds to the reaction, resulting in the observed difference between the bag-wall residue sample and the bulk sample.

In the solutions with $\mathrm{pH}=2$ and 4 , the most abundant eluates were detected at $3.0 \mathrm{~min}$. The corresponding mass spectra were characterized by the strong peak of ammonium adduct ions $\left[\left(\mathrm{C}_{3} \mathrm{H}_{4} \mathrm{O}\right)_{3}+\mathrm{NH}_{4}\right]^{+}$at $m / z$ 186.1125. Other major components were eluted at the retention times around 1.0 and $4.8 \mathrm{~min}$. However, the formula assignment showed that the main components in these eluates were neither pyridinium salts nor the oligomers of acrolein and propylene imine (Fig. S4). In other words, the reaction of acrolein with ammonia/ammonium was inhibited in the highly acidic solu- 
tions. A similar observation was made for other heterocyclic NOCs produced by carbonyl-to-imine conversion (Kampf et al., 2012). The formation of imine from the carbonyl requires a free electron pair on ammonia, which is reduced in abundance in an acidic environment due to the $\mathrm{pH}$-dependent equilibrium of ammonium ions and ammonia. In addition, the carbon number for many assigned formulae in the solutions with $\mathrm{pH}=2$ and 4 was not even the multiple of 3 , and some ions had very low DBE values. A possible reason could be that high acidity leads to the acid-catalyzed cleavage reaction of the acrolein and its polymers.

The products observed at various $\mathrm{pH}$ values were also examined using SERS and UV-vis adsorption spectroscopy. The Raman spectrum for 3-methylpyridine should be dominated by a band around the $1040 \mathrm{~cm}^{-1}$ region (assigned to the $\delta_{\text {ring }}$ and $\nu_{\text {ring }}$ fundamentals) and a band around the $1630 \mathrm{~cm}^{-1}$ region (symmetric ring stretching), with other characteristic bands with medium-weak intensity including those around 540 and $1230 \mathrm{~cm}^{-1}$ (Centeno et al., 2012; Guerrini et al., 2009). As shown in Fig. 7, these main characteristic Raman vibrations of 3-methylpyridine have been observed in the Raman spectra at $\mathrm{pH}=6$ but not at $\mathrm{pH}=10$. The observation of these frequencies further supports the assignment of $\left(\mathrm{C}_{3} \mathrm{H}_{4} \mathrm{O}\right)_{2} \mathrm{C}_{6} \mathrm{H}_{8} \mathrm{~N}^{+}$at $\mathrm{m} / z 206.1178$ to a pyridinium compound. The Raman spectra for the bulk solutions at $\mathrm{pH}=2$ have a larger number of vibrational peaks (e.g., from 800 to $1100 \mathrm{~cm}^{-1}$ ), which indicates a more complicated set of products was formed at high acidity. It is noted that the characteristic pyridine vibration around $1230 \mathrm{~cm}^{-1}$ was still observed at $\mathrm{pH}=2$, but in the HRMS analysis, the ions at $m / z 206.1178$ were not present $\mathrm{pH}=2$. This indicates that the products in $\mathrm{pH}=2$ still contain some pyridinium compounds, but $\left(\mathrm{C}_{3} \mathrm{H}_{4} \mathrm{O}\right)_{2} \mathrm{C}_{6} \mathrm{H}_{8} \mathrm{~N}^{+}$is no longer a major species.

The UV-vis absorption spectra for the bulk solutions can also reflect the influence of $\mathrm{pH}$ upon the liquid-phase products, as shown in Fig. 8a. For the solutions at $\mathrm{pH}=10$, the band near $300 \mathrm{~nm}$ is consistent with the absorption pattern of standard acrolein (the UV-vis spectra of acrolein and 3methylpyridine are shown in Fig. S5). The strong absorptivity for the wavelength shorter than $250 \mathrm{~nm}$ could result from the $\pi-\pi^{*}$ transitions involving conjugated bonds in the oligomers of acrolein and propylene imine. When the $\mathrm{pH}$ was adjusted to 6 , the UV-vis adsorption pattern was different from that for the alkaline solution. A band around 250$280 \mathrm{~nm}$ emerged, which is consistent with the characteristic UV absorption of 3-methylpyridine. Besides, the solution at $\mathrm{pH}=6$ possessed the absorptivity for visible radiation with wavelengths longer than $400 \mathrm{~nm}$. A weak absorption peak was even found in the band near $430 \mathrm{~nm}$, indicating the formation of even more efficient chromophores. However, if the $\mathrm{pH}$ value was further decreased to 2 , the absorbance at the visible wavelength dropped to almost zero. The possible reason for this drop could be acid-catalyzed degradation of oligomers and the removal of the conjugated bonds (which agrees with the UPLC ESI HRMS results). The con- version from acrolein to the chromophores and pyridinium compounds was more apparent in the UV-vis spectra of the solution at $\mathrm{pH}=6$ with varying reaction times. As shown in Fig. 8b, as the reaction went on, the band around 250 $280 \mathrm{~nm}$ corresponding to 3-methylpyridinium rose to replace the acrolein band around $300 \mathrm{~nm}$ as the prominent absorption for wavelength over $250 \mathrm{~nm}$. Meanwhile, the light absorption at the wavelength around $430 \mathrm{~nm}$ increased as well, implying the generation of chromophores. These observations suggest that the light-absorbing oligomers and pyridinium compounds can be formed from acrolein in the liquid phase on a timescale of a few hours.

\subsection{Atmospheric implications}

Reactions of carbonyl compounds with ammonia/ammonium to form hemiaminals and imines contribute to the formation of light-absorbing SOA in the atmosphere (De Haan et al., 2011; Hawkins et al., 2018; Lee et al., 2013; Powelson et al., 2014). In this work, we found that acrolein, the smallest $\alpha, \beta$-unsaturated aldehyde, has the potential to form heterocyclic NOCs, as shown in Fig. 9. Acrolein, though volatile, has a moderate solubility in water (its Henry's constant is $\sim 8 \mathrm{~mol} \mathrm{~L}^{-1} \mathrm{~atm}^{-1}$ ). Ammonia and ammonium ions are commonly observed in atmospheric particulate matter and cloud/fog droplets (Chang et al., 2016; Hu et al., 2011; Huang et al., 2012; Ye et al., 2011). In atmospheric waters, the dissolved acrolein can undergo reactions with ammonia/ammonium to form light-absorbing NOCs including the high molecular-weight oligomers and pyridinium compounds. The conversion from acrolein to pyridinium compounds occurs on a timescale of a few hours. This conversion time is comparable to that of the reaction of acrolein with $\mathrm{OH}$ and much shorter than that of the acrolein photolysis (Magneron et al., 2002). Therefore, the aqueous removal of acrolein could compete with its gas-phase oxidation. This assertion will need to be verified in future studies under conditions of the atmospherically more relevant acrolein and ammonia concentrations.

The formation of pyridinium compounds is strongly $\mathrm{pH}$ dependent. If atmospheric waters are neutral or mildly acidic, 3-methylpyridine is formed and continues to react with other carbonyl compounds to generate the involatile higherMW pyridinium SOA compounds. If atmospheric waters are alkaline, despite the formation of 3-methylpyridine via aqueous-phase reaction, the semi-volatile 3-methylpyridine will revolatilize to the gas phase. Though the reported $\mathrm{pH}$ values of atmospheric aerosol particles vary from 0 to 9 (Guo et al., 2015; Hennigan et al., 2015; Pszenny et al., 2004; Weber et al., 2016), alkaline conditions are much less common. Even under the ammonia-rich conditions, such as those found in the northern China winter haze, the fine particles are moderately acidic with a pH of around 5 (Song et al., 2018). Therefore, atmospheric acrolein can be taken up into the ammonium-containing aerosols with high RH to undergo the 


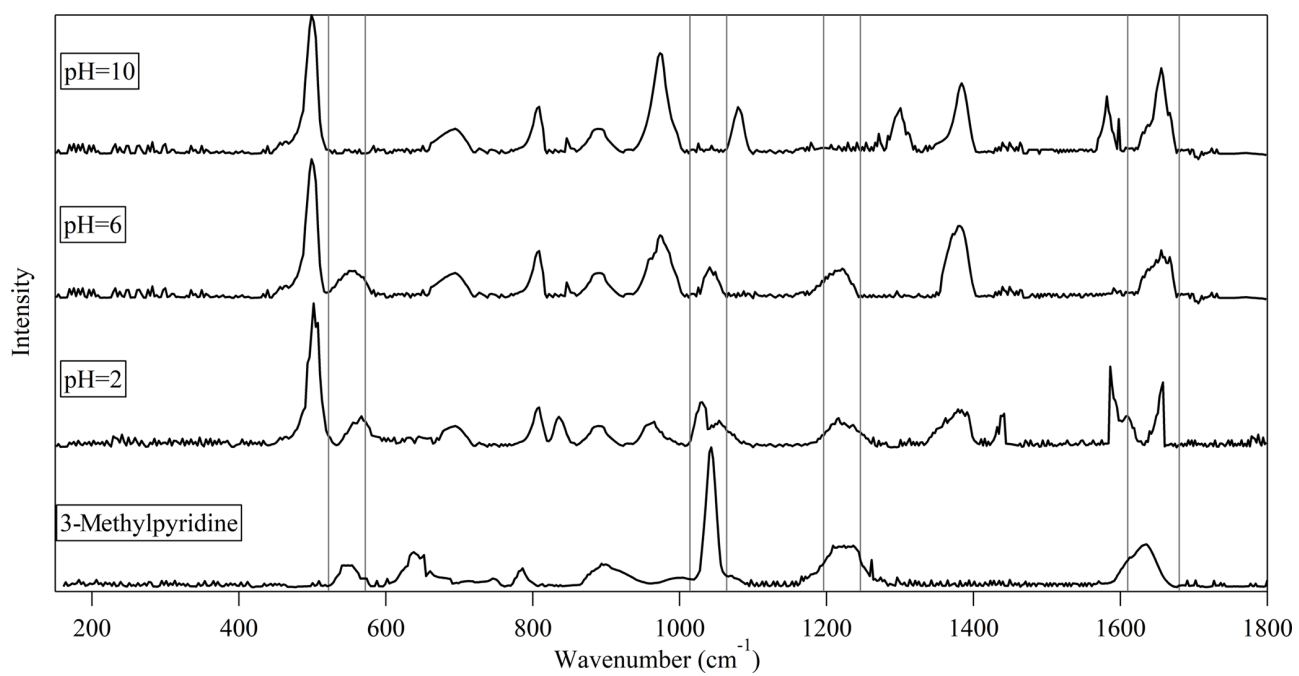

Figure 7. Surface-enhanced Raman spectra for the bulk solutions with different $\mathrm{pH}$ values after a bulk aqueous-phase reaction of acrolein with ammonium ion. The bottom panel shows a reference Raman spectrum of 3-methylpyridine.
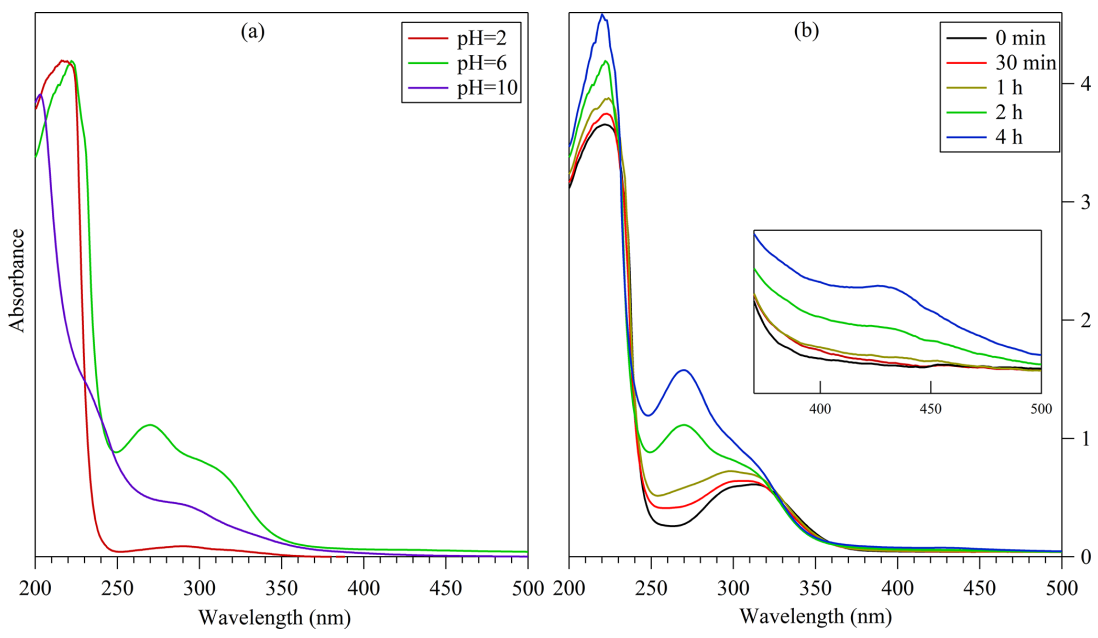

Figure 8. UV-vis absorption spectra (a) for the bulk solutions with different pH values after a bulk liquid-phase reaction of acrolein with ammonium ion for $2 \mathrm{~h}$ and (b) for the bulk solutions with $\mathrm{pH}=6$ after different durations of the reaction of acrolein with ammonium ion. The insert in panel (b) is the zoom-in spectra for the wavelength near $430 \mathrm{~nm}$.

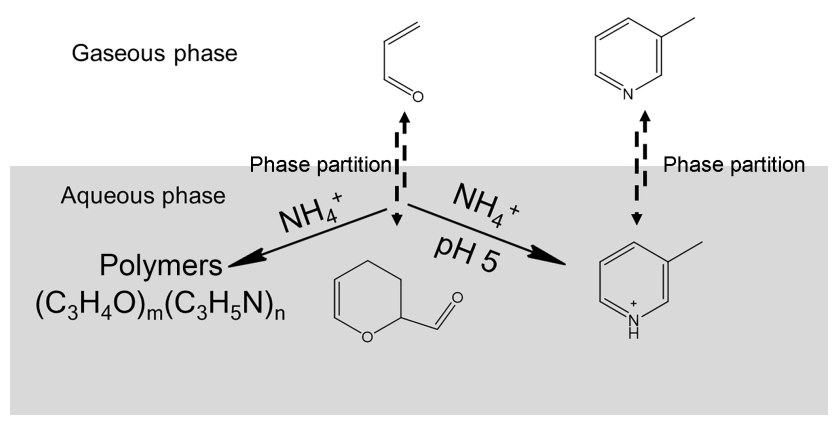

Figure 9. Proposed pathways to the formation of SOA compounds by the reaction of acrolein with ammonia or ammonium. atmospheric aqueous-phase reaction to be less volatile chromophores. The reactive uptake of $\alpha, \beta$-unsaturated aldehydes on aerosols should be taken into account as a source of lightabsorbing NOCs in SOA.

\section{Conclusion}

In conclusion, we studied acrolein, as a ubiquitous $\alpha, \beta$ unsaturated mono-carbonyl VOC in the atmosphere for its potential to form SOA in reactions with ammonia or ammonium. Tedlar bag experiments in the gas phase and on the bag walls, as well as bulk aqueous-phase experiments were carried out. We did the MS analysis for the gaseous components and the bag-wall residue samples in the reaction 
bag and for the bulk solutions. Gaseous 3-methylpyridine was observed in the acrolein-ammonia bag and acroleinammonium bag. Polymers and pyridinium compounds were observed in the liquid film on the wall of acrolein-ammonium bags and in the bulk solutions with ammonium. This demonstrated that, in the ammonium-containing aqueous phase, dissolved acrolein can react to become 3-methylpyridine, which partly revolatilizes back to the gas phase but mostly undergoes additional reaction to be pyridinium salts. The reaction rate for the pyridinium formation from acrolein is on a timescale of a few hours according at the concentrations used in this work. Moreover, the $\mathrm{pH}$ value is critical to the reaction of acrolein and ammonium in the aqueous phase. The formation of the pyridinium compounds is more favorable when the liquid phase is moderately acidic. Both the polymers of acroleins/propylene imines and the pyridinium compounds can increase the light absorptivity of aerosol particles. Since ammonium widely exists in the atmospheric aerosols, our work suggests that the reactive uptake of acrolein into aerosols is a potential atmospheric loss process for acrolein, which leads to the formation of nitrogencontaining, light-absorbing, heterocyclic SOA compounds.

Data availability. The basic properties of chemicals including the Henry's constant and the typical UV-vis spectra were obtained from NIST Chemistry WebBook, Standard Reference Database Number 69 (https://webbook.nist.gov/chemistry/, last access: 30 January 2019). The film $\mathrm{pH}$ on the walls of Tedlar bags was obtained according to the E-AIM model (http://www.aim.env.uea.ac.uk/aim/ aim.php, last access: 30 January 2019). All data shown in the figures and table in this paper (including the Supplement) are available from the corresponding authors upon request.

Supplement. The supplement related to this article is available online at: https://doi.org/10.5194/acp-19-1343-2019-supplement.

Author contributions. ZL, XL and XY designed the research. ZL performed the experiments. ZL and XL carried out the data analysis and wrote the manuscript. SN and XY edited the manuscript and provided advice on the organic chemistry. $\mathrm{HC}$ and JC reviewed and commented on the paper.

Competing interests. The authors declare that they have no conflict of interest.

Acknowledgements. This work was supported by the National Natural Science Foundation of China (nos. 21507010, 91544224, 41775150, 41827804, 91743202). The authors thank Chris Vanderwal for discussions of the possible chemical mechanisms.

Edited by: James Roberts

Reviewed by: three anonymous referees

\section{References}

Aiona, P. K., Lee, H. J., Lin, P., Heller, F., Laskin, A., Laskin, J., and Nizkorodov, S. A.: A Role for 2-Methyl Pyrrole in the Browning of 4-Oxopentanal and Limonene Secondary Organic Aerosol, Environ. Sci. Technol., 51, 11048-11056, https://doi.org/10.1021/acs.est.7b02293, 2017.

Altemose, B., Gong, J., Zhu, T., Hu, M., Zhang, L., Cheng, H., Zhang, L., Tong, J., Kipen, H. M., Ohman-Strickland, P., Meng, Q., Robson, M. G., and Zhang, J.: Aldehydes in relation to air pollution sources: A case study around the Beijing Olympics, Atmos. Environ., 109, 61-69, https://doi.org/10.1016/j.atmosenv.2015.02.056, 2015.

Baker, J., Arey, J., and Atkinson, R.: Formation and reaction of hydroxycarbonyls from the reaction of $\mathrm{OH}$ radicals with 1,3butadiene and isoprene, Environ. Sci. Technol., 39, 4091-4099, https://doi.org/10.1021/es047930t, 2005.

Bauer, R., du Toit, M., and Kossmann, J.: Influence of environmental parameters on production of the acrolein precursor 3hydroxypropionaldehyde by Lactobacillus reuteri DSMZ 20016 and its accumulation by wine lactobacilli, Int. J. Food Microbiol. 137, 28-31, https://doi.org/10.1016/j.ijfoodmicro.2009.10.012, 2010.

Bauer, R., Hiten, F., Crouch, A. M., Kossmann, J., and Burger, B. V.: Acrolein Dimer as a Marker for Direct Detection of Acrolein in Wine, South African J. Enol. Viticul., 33, 72-79, 2012.

Bones, D. L., Henricksen, D. K., Mang, S. A., Gonsior, M., Bateman, A. P., Nguyen, T. B., Cooper, W. J., and Nizkorodov, S. A.: Appearance of strong absorbers and fluorophores in limonene$\mathrm{O}_{3}$ secondary organic aerosol due to $\mathrm{NH}_{4}^{+}$-mediated chemical aging over long time scales, J. Geophys. Res., 115, D05203, https://doi.org/10.1029/2009JD012864, 2010.

Brody, F. and Ruby, P. R.: Synthetic and Natural Sources of the Pyridine Ring, in: Pyridine and Its Derivatives. Part I, Interscience Publishers Inc., New York, 613 pp., 1960.

Cahill, T. M.: Ambient Acrolein Concentrations in Coastal, Remote, and Urban Regions in California, Environ. Sci. Technol., 48, 8507-8513, https://doi.org/10.1021/es5014533, 2014.

Carlier, P., Hannachi, H., and Mouvier, G.: The chemistry of carbonyl-compounds in the atmosphere - a review, Atmos. Environ., 20, 2079-2099, https://doi.org/10.1016/00046981(86)90304-5, 1986.

Centeno, S. P., Lopez-Tocon, I., Roman-Perez, J., Arenas, J. F., Soto, J., and Otero, J. C.: Franck-Condon Dominates the Surface-Enhanced Raman Scattering of 3-Methylpyridine: Propensity Rules of the Charge-Transfer Mechanism under Reduced Symmetry, J. Phys. Chem. C., 116, 23639-23645, https://doi.org/10.1021/jp307015a, 2012.

Cerqueira, M. A., Pio, C. A., Gomes, P. A., Matos, J. S., and Nunes, T.: Volatile organic compounds in rural atmospheres of central Portugal, Sci. Total Environ., 313, 49-60, https://doi.org/10.1016/S0048-9697(03)00250-X, 2003.

Chang, Y., Zou, Z., Deng, C., Huang, K., Collett, J. L., Lin, J., and Zhuang, G.: The importance of vehicle emissions as a source of atmospheric ammonia in the megacity of Shanghai, Atmos. Chem. Phys., 16, 3577-3594, https://doi.org/10.5194/acp16-3577-2016, 2016.

Dai, W., Ho, S. S. H., Ho, K., and Cao, J.: Characterization of Particulate-Phase High Molecular Weight MonoCarbonyls $(\mathrm{C \#}>5)$ and Dicarbonyls in Urban Atmosphere 
of Xi'an, China, Aerosol Air Qual. Res., 12, 892-901, https://doi.org/10.4209/aaqr.2011.12.0228, 2012.

De Haan, D. O., Hawkins, L. N., Kononenko, J. A., Turley, J. J., Corrigan, A. L., Tolbert, M. A., and Jimenez, J. L.: Formation of Nitrogen-Containing Oligomers by Methylglyoxal and Amines in Simulated Evaporating Cloud Droplets, Environ. Sci. Technol., 45, 984-991, 2011.

Feng, Z., Hu, W., Hu, Y., and Tang, M.: Acrolein is a major cigarette-related lung cancer agent: Preferential binding at p53 mutational hotspots and inhibition of DNA repair, P. Natl Acad. Sci. USA, 103, 15404-15409, https://doi.org/10.1073/pnas.0607031103, 2006.

Flores, J. M., Washenfelder, R. A., Adler, G., Lee, H. J., Segev, L., Laskin, J., Laskin, A., Nizkorodov, S. A., Brown, S. S., and Rudich, Y.: Complex refractive indices in the near-ultraviolet spectral region of biogenic secondary organic aerosol aged with ammonia, Phys. Chem. Chem. Phys., 16, 10629-10642, https://doi.org/10.1039/c4cp01009d, 2014.

Galloway, M. M., Powelson, M. H., Sedehi, N., Wood, S. E., Millage, K. D., Kononenko, J. A., Rynaski, A. D., and De Haan, D. O.: Secondary Organic Aerosol Formation during Evaporation of Droplets Containing Atmospheric Aldehydes, Amines, and Ammonium Sulfate, Environ. Sci. Technol., 48, 14417-14425, https://doi.org/10.1021/es5044479, 2014.

Garland, R. M., Elrod, M. J., Kincaid, K., Beaver, M. R., Jimenez, J. L., and Tolbert, M. A.: Acid-catalyzed reactions of hexanal on sulfuric acid particles: Identification of reaction products, Atmos. Environ., 40, 6863-6878, https://doi.org/10.1016/j.atmosenv.2006.07.009, 2006.

Grosjean, D.: Formaldehyde and other carbonyls in LosAngeles ambient air, Environ. Sci. Technol., 16, 254-262, https://doi.org/10.1021/es00099a005, 1982.

Grosjean, D., Grosjean, E., and Gertler, A. W.: On-road emissions of carbonyls from light-duty and heavy-duty vehicles, Environ. Sci. Technol., 35, 45-53, https://doi.org/10.1021/es001326a, 2001.

Guerrini, L., Garcia-Ramos, J. V., Domingo, C., and SanchezCortes, S.: Nanosensors Based on Viologen Functionalized Silver Nanoparticles: Few Molecules Surface. Enhanced Raman Spectroscopy Detection of Polycyclic Aromatic Hydrocarbons in Interparticle Hot Spots, Anal. Chem., 81, 1418-1425, https://doi.org/10.1021/ac8021746, 2009.

Guo, H., Xu, L., Bougiatioti, A., Cerully, K. M., Capps, S. L., Hite Jr., J. R., Carlton, A. G., Lee, S.-H., Bergin, M. H., Ng, N. L., Nenes, A., and Weber, R. J.: Fine-particle water and $\mathrm{pH}$ in the southeastern United States, Atmos. Chem. Phys., 15, 5211-5228, https://doi.org/10.5194/acp-15-5211-2015, 2015.

Hawkins, L. N., Welsh, H. G., and Alexander, M. V.: Evidence for pyrazine-based chromophores in cloud water mimics containing methylglyoxal and ammonium sulfate, Atmos. Chem. Phys., 18, 12413-12431, https://doi.org/10.5194/acp-18-124132018, 2018.

Hennigan, C. J., Izumi, J., Sullivan, A. P., Weber, R. J., and Nenes, A.: A critical evaluation of proxy methods used to estimate the acidity of atmospheric particles, Atmos. Chem. Phys., 15, 27752790, https://doi.org/10.5194/acp-15-2775-2015, 2015.

Ho, S. and Yu, J. Z.: Concentrations of formaldehyde and other carbonyls in environments affected by incense burning, J. Environ. Monitor., 4, 728-733, https://doi.org/10.1039/b200998f, 2002.
Hu, D., Chen, J., Ye, X., Li, L., and Yang, X.: Hygroscopicity and evaporation of ammonium chloride and ammonium nitrate: Relative humidity and size effects on the growth factor, Atmos. Environ., 45, 2349-2355, https://doi.org/10.1016/j.atmosenv.2011.02.024, 2011.

Huang, Y., Chen, H., Wang, L., Yang, X., and Chen, J.: Single particle analysis of amines in ambient aerosol in Shanghai, Environ. Chem., 9, 202-210, doi:10.1071/en11145, 2012

Jang, M. S., Czoschke, N. M., Lee, S., and Kamens, R. M.: Heterogeneous atmospheric aerosol production by acidcatalyzed particle-phase reactions, Science, 298, 814-817, https://doi.org/10.1126/science.1075798, 2002.

Kampf, C. J., Jakob, R., and Hoffmann, T.: Identification and characterization of aging products in the glyoxal/ammonium sulfate system - implications for light-absorbing material in atmospheric aerosols, Atmos. Chem. Phys., 12, 6323-6333, https://doi.org/10.5194/acp-12-6323-2012, 2012.

Kampf, C. J., Filippi, A., Zuth, C., Hoffmann, T., and Opatz, T.: Secondary brown carbon formation via the dicarbonyl imine pathway: nitrogen heterocycle formation and synergistic effects, Phys. Chem. Chem. Phys., 18, 18353-18364, https://doi.org/10.1039/c6cp03029g, 2016.

Laskin, J., Laskin, A., Roach, P. J., Slysz, G. W., Anderson, G. A., Nizkorodov, S. A., Bones, D. L., and Nguyen, L. Q.: HighResolution Desorption Electrospray Ionization Mass Spectrometry for Chemical Characterization of Organic Aerosols, Anal. Chem., 82, 2048-2058, 2010.

Lee, A. K. Y., Zhao, R., Li, R., Liggio, J., Li, S., and Abbatt, J. P. D.: Formation of Light Absorbing Organo-Nitrogen Species from Evaporation of Droplets Containing Glyoxal and Ammonium Sulfate, Environ. Sci. Technol., 47, 12819-12826, https://doi.org/10.1021/es402687w, 2013.

Lin, P., Laskin, J., Nizkorodov, S. A., and Laskin, A.: Revealing Brown Carbon Chromophores Produced in Reactions of Methylglyoxal with Ammonium Sulfate, Environ. Sci. Technol., 49, 14257-14266, https://doi.org/10.1021/acs.est.5b03608, 2015.

Lipari, F., Dasch, J. M., and Scruggs, W. F.: Aldehyde emissions from wood-burning fireplaces, Environ. Sci. Technol., 18, 326330, https://doi.org/10.1021/es00123a007, 1984.

Liu, X. Y., Jeffries, H. E., and Sexton, K. G.: Hydroxyl radical and ozone initiated photochemical reactions of 1,3-butadiene, Atmos. Environ., 33, 3005-3022, https://doi.org/10.1016/S13522310(99)00078-3, 1999.

Magneron, I., Thevenet, R., Mellouki, A., Le Bras, G., Moortgat, G. K., and Wirtz, K.: A study of the photolysis and OH-initiated oxidation of acrolein and trans-crotonaldehyde, J. Phys. Chem. A, 106, 2526-2537, https://doi.org/10.1021/jp013413a, 2002.

Maxut, A., Noziere, B., Fenet, B., and Mechakra, H.: Formation mechanisms and yields of small imidazoles from reactions of glyoxal with $\mathrm{NH}_{4}^{+}$in water at neutral $\mathrm{pH}$, Phys. Chem. Chem. Phys., 17, 20416-20424, https://doi.org/10.1039/c5cp03113c, 2015.

Mellouki, A., Wallington, T. J., and Chen, J.: Atmospheric Chemistry of Oxygenated Volatile Organic Compounds: Impacts on Air Quality and Climate, Chem. Rev., 115, 3984-4014, https://doi.org/10.1021/cr500549n, 2015.

Nozière, B. and Esteve, W.: Light-absorbing aldol condensation products in acidic aerosols: Spectra, kinetics, and contribution to the absorption index, Atmos. Environ., 41, 1150-1163, 2007. 
Nozière, B. and Córdova, A.: A kinetic and mechanistic study of the amino acid catalyzed aldol condensation of acetaldehyde in aqueous and salt solutions, J. Phys. Chem. A, 112, 2827-2837, https://doi.org/10.1021/jp7096845, 2008.

Nozière, B., Voisin, D., Longfellow, C. A., Friedli, H., Henry, B. E., and Hanson, D. R.: The Uptake of Methyl Vinyl Ketone, Methacrolein, and 2-Methyl-3-butene-2-ol onto Sulfuric Acid Solutions, J. Phys. Chem. A, 110, 2387-2395, https://doi.org/10.1021/jp0555899, 2006.

O’Brien, R. E., Laskin, A., Laskin, J., Liu, S., Weber, R., Russell, L. M., and Goldstein, A. H.: Molecular characterization of organic aerosol using nanospray desorption/electrospray ionization mass spectrometry: CalNex 2010 field study, Atmos. Environ., 68, 265-272, 2013.

Orlando, J. J. and Tyndall, G. S.: Mechanisms for the reactions of $\mathrm{OH}$ with two unsaturated aldehydes: Crotonaldehyde and acrolein, J. Phys. Chem. A, 106, 12252-12259, https://doi.org/10.1021/jp021530f, 2002.

Phillips, S. M., Bellcross, A. D., and Smith, G. D.: Light Absorption by Brown Carbon in the Southeastern United States is pH-dependent, Environ. Sci. Technol., 51, 6782-6790, https://doi.org/10.1021/acs.est.7b01116, 2017.

Powelson, M. H., Espelien, B. M., Hawkins, L. N., Galloway, M. M., and De Haan, D. O.: Brown Carbon Formation by Aqueous-Phase Carbonyl Compound Reactions with Amines and Ammonium Sulfate, Environ. Sci. Technol., 48, 985-993, https://doi.org/10.1021/es4038325, 2014.

Pszenny, A. A. P., Moldanová, J., Keene, W. C., Sander, R., Maben, J. R., Martinez, M., Crutzen, P. J., Perner, D., and Prinn, R. G.: Halogen cycling and aerosol $\mathrm{pH}$ in the Hawaiian marine boundary layer, Atmos. Chem. Phys., 4, 147-168, https://doi.org/10.5194/acp-4-147-2004, 2004.

Reda, A. A., Schnelle-Kreis, J., Orasche, J., Abbaszade, G., Lintelmann, J., Arteaga-Salas, J. M., Stengel, B., Rabe, R., Harndorf, H., Sippula, O., Streibel, T., and Zimmermann, R.: Gas phase carbonyl compounds in ship emissions: Differences between diesel fuel and heavy fuel oil operation, Atmos. Environ., 112, 369380, https://doi.org/10.1016/j.atmosenv.2015.03.058, 2015.

Renard, P., Siekmann, F., Salque, G., Demelas, C., Coulomb, B., Vassalo, L., Ravier, S., Temime-Roussel, B., Voisin, D., and Monod, A.: Aqueous-phase oligomerization of methyl vinyl ketone through photooxidation - Part 1: Aging processes of oligomers, Atmos. Chem. Phys., 15, 21-35, https://doi.org/10.5194/acp-15-21-2015, 2015.

Renard, P., Tlili, S., Ravier, S., Quivet, E., and Monod, A.: Aqueous phase oligomerization of alpha,beta-unsaturated carbonyls and acids investigated using ion mobility spectrometry coupled to mass spectrometry (IMS-MS), Atmos. Environ., 130, 153-162, https://doi.org/10.1016/j.atmosenv.2015.10.060, 2016.

Rodriguez, A. A., de Loera, A., Powelson, M. H., Galloway, M. M., and De Haan, D. O.: Formaldehyde and Acetaldehyde Increase Aqueous-Phase Production of Imidazoles in Methylglyoxal/Amine Mixtures: Quantifying a Secondary Organic Aerosol Formation Mechanism, Environ. Sci. Technol. Lett., 4, 234-239, https://doi.org/10.1021/acs.estlett.7b00129, 2017.

Romagnoli, P., Balducci, C., Perilli, M., Perreca, E., and Cecinato, A.: Particulate PAHs and n-alkanes in the air over Southern and Eastern Mediterranean Sea, Chemosphere, 159, 516-525, https://doi.org/10.1016/j.chemosphere.2016.06.024, 2016.
Sareen, N., Schwier, A. N., Shapiro, E. L., Mitroo, D., and McNeill, V. F.: Secondary organic material formed by methylglyoxal in aqueous aerosol mimics, Atmos. Chem. Phys., 10, 997-1016, https://doi.org/10.5194/acp-10-997-2010, 2010.

Seaman, V. Y., Bennett, D. H. and Cahill, T. M.: Origin, occurrence, and source emission rate of acrolein in residential indoor air, Environ. Sci. Technol., 41, 6940-6946, https://doi.org/10.1021/es0707299, 2007.

Shapiro, E. L., Szprengiel, J., Sareen, N., Jen, C. N., Giordano, M. R., and McNeill, V. F.: Light-absorbing secondary organic material formed by glyoxal in aqueous aerosol mimics, Atmos. Chem. Phys., 9, 2289-2300, https://doi.org/10.5194/acp-9-2289-2009, 2009.

Shen, X., Wu, H., Zhao, Y., Huang, D., Huang, L., and Chen, Z.: Heterogeneous reactions of glyoxal on mineral particles: A new avenue for oligomers and organosulfate formation, Atmos. Environ., 131, 133-140, https://doi.org/10.1016/j.atmosenv.2016.01.048, 2016.

Song, S., Gao, M., Xu, W., Shao, J., Shi, G., Wang, S., Wang, Y., Sun, Y., and McElroy, M. B.: Fine-particle $\mathrm{pH}$ for Beijing winter haze as inferred from different thermodynamic equilibrium models, Atmos. Chem. Phys., 18, 7423-7438, https://doi.org/10.5194/acp-18-7423-2018, 2018.

Stitz, F.: Über eine Synthese von b-Picolin aus Acrolein und Ammoniak und die Umwandlung von b-Picolin durch Chlorierung in Nikotinsäure, Österreichische Chemiker Zeitung, 45, 159-162, 1942.

Takahama, S., Pathak, R. K., and Pandis, S. N.: Efflorescence transitions of ammonium sulfate particles coated with secondary organic aerosol, Environ. Sci. Technol., 41, 2289-2295, https://doi.org/10.1021/es0619915, 2007.

Teich, M., van Pinxteren, D., Kecorius, S., Wang, Z., and Herrmann, H.: First Quantification of Imidazoles in Ambient Aerosol Particles: Potential Photosensitizers, Brown Carbon Constituents, and Hazardous Components, Environ. Sci. Technol., 50, 1166-1173, https://doi.org/10.1021/acs.est.5b05474, 2016.

Trainic, M., Abo Riziq, A., Lavi, A., Flores, J. M., and Rudich, Y.: The optical, physical and chemical properties of the products of glyoxal uptake on ammonium sulfate seed aerosols, Atmos. Chem. Phys., 11, 9697-9707, https://doi.org/10.5194/acp11-9697-2011, 2011.

Tschitschibabin, A. E.: Über Kondensationen der Aldehyde mit Ammonik zu Pyridinbasen, J. Prakt. Chem., 107, 122-128, 1924.

Tschitschibabin, A. E. and Oparina, M. P.: Über die Kondensation des Crotonaldehyds mit Ammoniak bei Gegenwart von Aluminiumoxyd, Ber. Dtsch. Chem. Ges. A/B, 60, 1877-1879, 1927.

Tuazon, E. C., Alvarado, A., Aschmann, S. M., Atkinson, R., and Arey, J.: Products of the gas-phase reactions of 1,3-butadiene with $\mathrm{OH}$ and $\mathrm{NO}_{3}$ radicals, Environ. Sci. Technol., 33, 35863595, https://doi.org/10.1021/es990193u, 1999.

Umano, K. and Shibamoto, T.: Analysis of acrolein from heated cooking oils and beef fat, J. Agr. Food Chem., 35, 909-912, https://doi.org/10.1021/jf00078a014, 1987.

Updyke, K. M., Nguyen, T. B., and Nizkorodov, S. A.: Formation of brown carbon via reactions of ammonia with secondary organic aerosols from biogenic and anthropogenic precursors, Atmos. Environ., 63, 22-31, https://doi.org/10.1016/j.atmosenv.2012.09.012, 2012. 
Van Wyngarden, A. L., Pérez-Montaño, S., Bui, J. V. H., Li, E. S. W., Nelson, T. E., Ha, K. T., Leong, L., and Iraci, L. T.: Complex chemical composition of colored surface films formed from reactions of propanal in sulfuric acid at upper troposphere/lower stratosphere aerosol acidities, Atmos. Chem. Phys., 15, 42254239, https://doi.org/10.5194/acp-15-4225-2015, 2015.

Volkamer, R., Martini, F. S., Molina, L. T., Salcedo, D., Jimenez, J. L., and Molina, M. J.: A missing sink for gas-phase glyoxal in Mexico City: Formation of secondary organic aerosol, Geophys. Res. Lett., 34, L1980719, https://doi.org/10.1029/2007GL030752, 2007.

Wang, X., Gao, S., Yang, X., Chen, H., Chen, J., Zhuang, G., Surratt, J. D., Chan, M. N., and Seinfeld, J. H.: Evidence for High Molecular Weight Nitrogen-Containing Organic Salts in Urban Aerosols, Environ. Sci. Technol., 44, 4441-4446, https://doi.org/10.1021/es1001117, 2010.

Weber, R. J., Guo, H., Russell, A. G., and Nenes, A.: High aerosol acidity despite declining atmospheric sulfate concentrations over the past 15 years, Nat. Geosci., 9, 282-285, https://doi.org/10.1038/NGEO2665, 2016.

Yasmeen, F., Sauret, N., Gal, J.-F., Maria, P.-C., Massi, L., Maenhaut, W., and Claeys, M.: Characterization of oligomers from methylglyoxal under dark conditions: a pathway to produce secondary organic aerosol through cloud processing during nighttime, Atmos. Chem. Phys., 10, 3803-3812, https://doi.org/10.5194/acp-10-3803-2010, 2010.
Ye, X., Ma, Z., Zhang, J., Du, H., Chen, J., Chen, H., Yang, X., Gao, W., and Geng, F.: Important role of ammonia on haze formation in Shanghai, Environ. Res. Lett., 6, 0240192, doi:10.1088/17489326/6/2/024019, 2011

Youngman, E. and Rust, F. F.: Production of allyl acrylate from acrolein, United States Patent Office, Patent Number 2991306, 1961.

Yu, G., Bayer, A. R., Galloway, M. M., Korshavn, K. J., Fry, C. G., and Keutsch, F. N.: Glyoxal in Aqueous Ammonium Sulfate Solutions: Products, Kinetics and Hydration Effects, Environ. Sci. Technol., 45, 6336-6342, https://doi.org/10.1021/es200989n, 2011.

Zhang, X., Luo, C., Huang, C., Chen, B., Huang, D., Pan, J., and Chao, Z.: Synthesis of 3-picoline from acrolein and ammonia through a liquid-phase reaction pathway using $\mathrm{SO}_{4}^{2-} / \mathrm{ZrO}_{2}-\mathrm{FeZSM}-5$ as catalyst, Chem. Eng. J., 253, 544553, https://doi.org/10.1016/j.cej.2014.03.072, 2014.

Zhang, X., Wu, Z., and Chao, Z.: Mechanism of pyridine bases prepared from acrolein and ammonia by in situ infrared spectroscopy, J. Mol. Catal. A-Chem., 411, 19-26, https://doi.org/10.1016/j.molcata.2015.08.014, 2016.

Zhao, J., Levitt, N. P., Zhang, R., and Chen, J.: Heterogeneous reactions of methylglyoxal in acidic media: Implications for secondary organic aerosol formation, Environ. Sci. Technol., 40, 7682-7687, https://doi.org/10.1021/es060610k, 2006. 